\title{
Evolução da anatomia radicular do milho 'Saracura' em ciclos de seleção sucessivos
}

\author{
Fabricio José Pereira( ${ }^{(1)}$ Evaristo Mauro de Castro(1), Thiago Corrêa de Souza ${ }^{(1)}$ \\ e Paulo César Magalhães ${ }^{(2)}$
}

\begin{abstract}
(1) Universidade Federal de Lavras, Departamento de Biologia, Setor de Fisiologia Vegetal, Campus Universitário, Caixa Postal 37, CEP 37200-000 Lavras, MG. E-mail: fjprock@hotmail.com, emcastro@ufla.br, thiagonepre@hotmail.com (2)Embrapa Milho e Sorgo, Caixa Postal 151, CEP 35701-970 Sete Lagoas, MG. E-mail: pcesar@cnpms.embrapa.br
\end{abstract}

\begin{abstract}
Resumo - Este trabalho teve como objetivo verificar as modificações nas características anatômicas radiculares relacionadas à hipoxia, durante 18 ciclos de seleção da variedade de milho (Zea mays) BRS 4154 Saracura, adaptada a áreas sujeitas a alagamento. A variedade BR 107 e o híbrido simples BRS 1010, suscetíveis ao alagamento, foram utilizados como controle. As diferentes cultivares foram submetidas a alagamentos intermitentes, a cada dois dias, durante dois meses. As amostras radiculares foram preparadas e analisadas em microscopia óptica. Em relação ao grupo controle e aos ciclos anteriores de seleção, a BRS 4154 teve aumento na formação de aerênquima, diminuição do córtex, diminuição do diâmetro dos vasos, diminuição da camada subepidérmica, aumento na espessura do floema e epiderme. Os sucessivos ciclos de seleção melhoraram as características do milho 'Saracura' e sua tolerância a ambientes alagados.
\end{abstract}

Termos para indexação: Zea mays, aerênquima, alagamento do solo, hipoxia, tolerância a ambientes alagados.

\section{Evolution of the root anatomy of 'Saracura' maize in successive selection cycles}

\begin{abstract}
This work aimed to verify the modifications in the root anatomical characteristics related to hypoxia, along 18 selection cycles of the maize (Zea mays) cultivar BRS 4154 Saracura, adapted to areas subject to flooding. Cultivars not tolerant to fooding, BR 107 and the simple hybrid BRS 1010, were used as controls. The different cultivars were subjected to intermittent soil waterlogging every two days for two months. The root samples were prepared and analyzed through light microscopy. Compared to the controls group and to early selection cycles, BRS 4154 had increased development of aerenchyma, decreased cortex thickness, decreased metaxylem diameter, decreased subepidermal layer, and increased epidermis and phloem thickness. The successive selection cycles improved 'Saracura' maize characteristics and its tolerance to flooding environments.
\end{abstract}

Index terms: Zea mays, aerenchyma, soil waterlogging, hypoxia, tolerance to flooding.

\section{Introdução}

O alagamento é um fator ambiental relativamente comumemáreascultivadas doplanetaegeradificuldades para a produção agrícola e florestal (Andrade et al., 1999). Ambientes sujeitos ao alagamento, como as florestas de galeria, o Pantanal e os chamados solos de várzea (Andrade et al., 1999), são resultantes de alagamento periódico, na época das chuvas, ou de cheias de rios. No Brasil, aproximadamente 28 milhões de hectares de terras sofrem alagamento e possuem potencial como terras cultiváveis (Vitorino et al., 2001).

O alagamento pode ser provocado por fatores naturais como elevação dos níveis dos rios, ação de tempestades, cheias periódicas, drenagem inadequada do solo ou, ainda, por fatores antrópicos, como o excesso de irrigação (Kozlowski, 1997). Tais fatores podem levar à condição de anoxia ou hipoxia, a depender da disponibilidade de oxigênio do solo onde a planta cresce. Nessas condições, fica impossível manter o metabolismo aeróbio e a produção de energia suficiente para que a planta cresça adequadamente (Kozlowski, 1984). Essa redução no crescimento da planta está relacionada aos seguintes fatores: diminuição da produção de ATP, resultante do metabolismo anaeróbio; fechamento estomático, com redução na captação de $\mathrm{CO}_{2}$; menor fotossíntese; menor absorção de nutrientes e translocação de carboidratos; além do 
desencadeamento da expressão de proteínas específicas de estresse anaeróbio, os chamados polipeptídeos anaeróbios (ANP) (Kozlowski, 1984; Liao \& Lin, 2001).

As plantas em condições de alagamento podem produzir o aerênquima, que é um tecido especializado em armazenamento de oxigênio, produzido pela apoptose celular desencadeada pelo etileno (Drew, 1997). A formação do aerênquima pode, ainda, ser induzida por outros fatores ambientais como a deficiência nutricional, a exemplo do que ocorre quando há deficiência de enxofre ao longo de uma grande extensão da raiz, que pode levar à formação de raízes adventícias (Bouranis et al., 2006). Vaselati et al. (2001) observaram que as raízes de plantas de Paspalum dilatatum, sob alagamento, desenvolvem aerênquima até proporções comparáveis às de plantas de ambiente alagado, e também alterações no diâmetro dos vasos do xilema. Outro parâmetro radicular que pode ser alterado com o alagamento é a porosidade das raízes, que está relacionada à difusão de gases pelos tecidos (Insausti et al., 2001).

A formação de aerênquima em raízes de milho ocorre em resposta ao estresse por hipoxia (Vasellati et al., 2001). Essa formação é do tipo lisígena e começa na região central do córtex para, posteriormente, se espalhar de forma radial e tangencial (Bouranis et al., 2006). O desenvolvimento do aerênquima leva à formação de espaços intercelulares, conectados ao longo do eixo da raiz, que facilitam a difusão de gases (Gunawardena, 2008) e, conseqüentemente, permitem melhor distribuição do $\mathrm{O}_{2}$ nos tecidos das plantas.

O milho é classificado como planta sensível ao estresse por anoxia. A variedade Saracura BRS-4154 foi desenvolvida pela Embrapa Milho e Sorgo para resistir a períodos de alagamento e, assim, tornar possível a sua produção nas diversas regiões onde ocorre este tipo de estresse. Essa variedade foi melhorada para a produção, a sobrevivência e a capacidade para o desenvolvimento de aerênquima nas raízes e na parte aérea da planta (Alves et al., 2002).

A literatura apresenta trabalhos que evidenciam os ganhos nas características fisiológicas e morfológicas quanto à resistência ao alagamento, proporcionados pela seleção, já na geração $\mathrm{F}_{1}$ de genótipos de Iris sp. (Johnston et al., 2004). Em Arabdopsis, observou-se que a seleção de plântulas sob alagamento resultou em melhoria nas características morfológicas e vegetativas de plantas da geração $\mathrm{F}_{3}$, em relação às de $\mathrm{F}_{1}$, tais como: incrementos na massa de matéria seca da parte aérea e no número de ramos laterais (Kolodynska \& Pigliucci, 2003)

Até o momento, não há trabalhos que tratem do efeito que sucessivos ciclos de seleção genética possam ter sobre a capacidade de produção de modificações anatômicas, para melhorar a tolerância de plantas a condições de hipoxia.

Este trabalho teve como objetivo avaliar o efeito de sucessivos ciclos de seleção sobre as estruturas anatômicas radiculares do milho BRS 4154 'Saracura', relacionadas à tolerância ao alagamento.

\section{Material e Métodos}

O experimento foi conduzido em casa de vegetação, nas áreas experimentais da Embrapa Milho e Sorgo, em Sete Lagoas, MG, e as análises anatômicas foram realizadas no Laboratório de Anatomia Vegetal, da Universidade Federal de Lavras, em Lavras, MG. O milho 'Saracura' está atualmente no seu 18 - ciclo anual de seleção, durante os quais ele tem sido submetido ao alagamento intermitente em campo (após o estádio V6), por meio de inundação controlada.As plantas com melhores resultados fisiológicos e de produção têm sido selecionadas, e as cariopses plantadas no ano seguinte (Alves et al., 2002). Neste experimento, os ciclos de seleção foram codificados como $\mathrm{C} 1$ a $\mathrm{C} 18$.

Vasos com $20 \mathrm{~L}$ foram preenchidos com solo de várzea - Planossolo Hidromórfico eutrófico arênico - adubado com: 0,075 $\mathrm{g} \mathrm{kg}^{-1}$ de sulfato de amônia, em duas aplicações semanais; $0,0333 \mathrm{~g} \mathrm{~kg}^{-1}$ de uréia, em quatro aplicações semanais; $0,3 \mathrm{~g} \mathrm{~kg}^{-1}$ de $\mathrm{Zn}$; e $1 \mathrm{~mL} \mathrm{~kg}^{-1}$ de deltametrina (Ferrer et al., 2005), em três doses semanais.

Os ciclos de seleção escolhidos para estudo foram: C1, C3, C5, C7, C9, C11, C13, C15, C17 e C18, além da variedade BR 107 - sensível ao alagamento - e do híbrido simples BRS 1010, que não é tolerante ao alagamento, mas também não é tão sensível quanto a BR 107, como testemunhas. Foram semeadas seis sementes por vaso, com desbaste, mais tarde, para duas plantas. $\mathrm{O}$ delineamento experimental foi inteiramente ao acaso, com um vaso por parcela, e quatro repetições.

As plantas foram submetidas ao encharcamento do solo no estádio de seis folhas completamente desenvolvidas, já com o ponto de crescimento acima da superfície do solo. A adubação em cobertura foi realizada com 
$100 \mathrm{~kg} \mathrm{ha}^{-1}$ de N; divididos em 10 aplicações semanais de $10 \mathrm{~kg} \mathrm{ha}^{-1}$ de N (Ferrer et al., 2005). O encharcamento foi realizado a cada dois dias, quando os vasos eram completamente encharcados e deixados sem adição de água até a próxima aplicação.

A coleta das amostras de raízes, para análise anatômica, ocorreu durante o período de 2 meses, em relação à primeira aplicação do alagamento nas amostras. Foram coletadas amostras de 5 raízes completas - com as regiões apical, de alongamento, pelífera e basal amostradas aleatoriamente em cada planta das parcelas. O solo foi removido dos vasos, as raízes foram lavadas em água corrente e, posteriormente, cortadas em seu ponto de inserção no caule, com uma tesoura. As raízes amostradas foram fixadas em solução de formaldeído, ácido acético e etanol 70\% (FAA 70) (Johansen, 1940), por 48 horas e, em seguida, preservadas em etanol $70 \%$, até a data das análises. As raízes foram cortadas a $4 \pm 0,5 \mathrm{~cm}$ a partir do ápice radicular (Melo et al., 2007). Esses fragmentos de raízes foram utilizados para a realização de cortes transversais em micrótomo de mesa. Os cortes foram clarificados com hipoclorito de sódio a $5 \%$, por $10 \mathrm{~min}$, reidratados por $10 \mathrm{~min}$, corados com astrablau (solução de safranina e azul de astra 7,5:2,5) e montados em lâminas com glicerina $50 \%$ (Kraus \& Arduin, 1997).

Foi utilizado microscópio óptico acoplado a uma câmera digital, com a qual foram realizadas fotografias dos cortes. Estas foram utilizadas para as medições dos parâmetros anatômicos, pelo programa de análise de imagem Imagetool, calibrado com régua microscópica fotografada nos mesmos aumentos das fotografias.
Os parâmetros anatômicos mensurados foram: área total de aerênquima (AAE); proporção ocupada pelo aerênquima no córtex (PA); proporção da área do cilindro vascular em relação à área total da raiz (PCV); proporção da área do córtex, em relação à área total da raiz (PC); espessura do córtex (EC); espessura da camada de células suberizadas, presentes na região da hipoderme (CS); circunferência total da raiz (CT); circunferência do cilindro vascular $(\mathrm{CC})$; proporção entre a circunferência do cilindro vascular e a circunferência total (PP); diâmetro das células corticais (CC); espessura da epiderme (EP); espessura da endoderme (EN); diâmetro das células do metaxilema (DX); diâmetro das células do parênquima do cilindro vascular (CCV); e a espessura do floema, no cilindro vascular (FL). Foram realizadas quatro medições de cada característica anatômica, em cada repetição, para a determinação das médias. A proporção da área ocupada pelo aerênquima no córtex foi calculada com base na divisão da área total de aerênquima formado pela área total do córtex.

Os dados foram testados, quanto à normalidade, pelo teste de Shapiro-Wilk, e quanto à homocedacidade, pelo teste de Lavene, e apresentaram distribuição normal e variâncias homogêneas. Utilizaram-se a análise de variância e o teste de Skott-Knott, a 5\% de probabilidade, para a análise estatística dos resultados.

\section{Resultados e Discussão}

Observou-se aumento significativo na AAE ao longo dos ciclos de seleção, e esse parâmetro representou, no primeiro ciclo $(\mathrm{C} 1)$, apenas $10,8 \%$ da área do último

Tabela 1. Valores observados relacionados à formação de aerênquima e à condutividade hidráulica, nos tecidos radiculares de milho 'Saracura', ao longo de sucessivos ciclos de seleção (C1 a C18), e de cultivares-testemunha (BR 107 e BRS 1010), em condições de alagamento intermitente ${ }^{(1)}$.

\begin{tabular}{|c|c|c|c|c|c|c|}
\hline $\begin{array}{l}\text { Ciclos de seleção e } \\
\text { testemunhas }\end{array}$ & $\begin{array}{l}\mathrm{AAE} \\
\left(\mathrm{mm}^{2}\right)\end{array}$ & $\begin{array}{l}\text { PA } \\
(\%)\end{array}$ & $\begin{array}{c}\mathrm{PCV} \\
(\%)\end{array}$ & $\begin{array}{l}\mathrm{PC} \\
(\%)\end{array}$ & $\begin{array}{c}\mathrm{EC} \\
(\mu \mathrm{m})\end{array}$ & $\begin{array}{l}\mathrm{CS} \\
(\mu \mathrm{m})\end{array}$ \\
\hline$\overline{\mathrm{C} 1}$ & $0,21 \mathrm{~d}$ & $8,22 \mathrm{c}$ & $0,32 \mathrm{a}$ & $0,68 \mathrm{a}$ & $615,04 a$ & $60,56 b$ \\
\hline $\mathrm{C} 3$ & $0,23 \mathrm{~d}$ & $10,69 \mathrm{c}$ & $0,25 \mathrm{a}$ & $0,76 a$ & $715,08 \mathrm{a}$ & $149,96 a$ \\
\hline $\mathrm{C} 5$ & $0,52 \mathrm{c}$ & $35,37 \mathrm{~b}$ & $0,18 \mathrm{a}$ & $0,82 \mathrm{a}$ & $556,97 \mathrm{~b}$ & $93,23 b$ \\
\hline $\mathrm{C} 7$ & $0,80 \mathrm{~b}$ & $33,16 b$ & $0,29 \mathrm{a}$ & $0,71 \mathrm{a}$ & $482,09 b$ & $71,41 b$ \\
\hline C9 & $1,02 b$ & $34,59 \mathrm{~b}$ & $0,26 a$ & $0,74 \mathrm{a}$ & $673,68 \mathrm{a}$ & $117,41 \mathrm{a}$ \\
\hline C11 & $1,05 b$ & $34,11 \mathrm{~b}$ & $0,30 \mathrm{a}$ & $0,70 \mathrm{a}$ & $531,98 b$ & $91,91 b$ \\
\hline $\mathrm{C} 13$ & $0,69 c$ & $41,91 \mathrm{a}$ & $0,24 a$ & $0,75 \mathrm{a}$ & $601,72 b$ & $99,46 b$ \\
\hline C15 & $0,44 \mathrm{c}$ & $42,17 \mathrm{a}$ & $0,30 \mathrm{a}$ & $0,70 \mathrm{a}$ & $446,39 b$ & $100,00 a$ \\
\hline C17 & $0,92 b$ & $47,53 \mathrm{a}$ & $0,27 \mathrm{a}$ & $0,73 a$ & $483,67 b$ & $81,26 b$ \\
\hline $\mathrm{C} 18$ & $1,95 \mathrm{a}$ & $46,59 \mathrm{a}$ & $0,24 \mathrm{a}$ & $0,76 \mathrm{a}$ & $476,90 \mathrm{~b}$ & $68,81 b$ \\
\hline BR 107 & $0,04 d$ & $1,71 \mathrm{c}$ & $0,30 \mathrm{a}$ & $0,70 \mathrm{a}$ & $657,21 \mathrm{a}$ & $134,53 \mathrm{a}$ \\
\hline BRS 1010 & $0,90 \mathrm{~b}$ & $35,31 \mathrm{~b}$ & $0,30 \mathrm{a}$ & $0,70 \mathrm{a}$ & $465,10 \mathrm{~b}$ & $88,57 \mathrm{~b}$ \\
\hline
\end{tabular}

${ }^{(1)}$ Médias seguidas por letras iguais, nas colunas, não diferem entre si pelo teste de Skott-Knott, a 5\% de probabilidade; AAE, área de aerênquima, encontrada no córtex; PA, proporção de aerênquima encontrado no córtex; PCV, proporção do cilindro vascular, em relação à área total da raiz; PC, proporção do córtex em relação à área total da raiz; EC, espessura do córtex; CS, espessura da camada de células suberizadas, presentes na região da hipoderme. 
ciclo de seleção (Tabela 1). Em comparação com a testemunha 'BR 107', o incremento na AAE foi ainda mais acentuado; a AAE dessa variedade representou apenas $2 \%$ da encontrada no C18. O híbrido BRS 1010 apresentou áreas de aerênquima mais altas que a outra testemunha, com valores semelhantes aos observados nos ciclos intermediários de seleção, mas menores do que o apresentado pelo C18 (Tabela 1 e Figura 1).
Vasellati et al. (2001) observaram aumento na área total do aerênquima, em Paspalum dilatatum, sob condições de alagamento. $\mathrm{O}$ aumento observado em AAE, nos últimos ciclos, no presente trabalho, resultou em PA muito superior à encontrada no híbrido LG-2447, cuja formação de aerênquima não ultrapassou $26 \%$ da área do córtex (Bouranis et al., 2006). O ganho em volume de aerênquima pode ser ainda mais elevado,

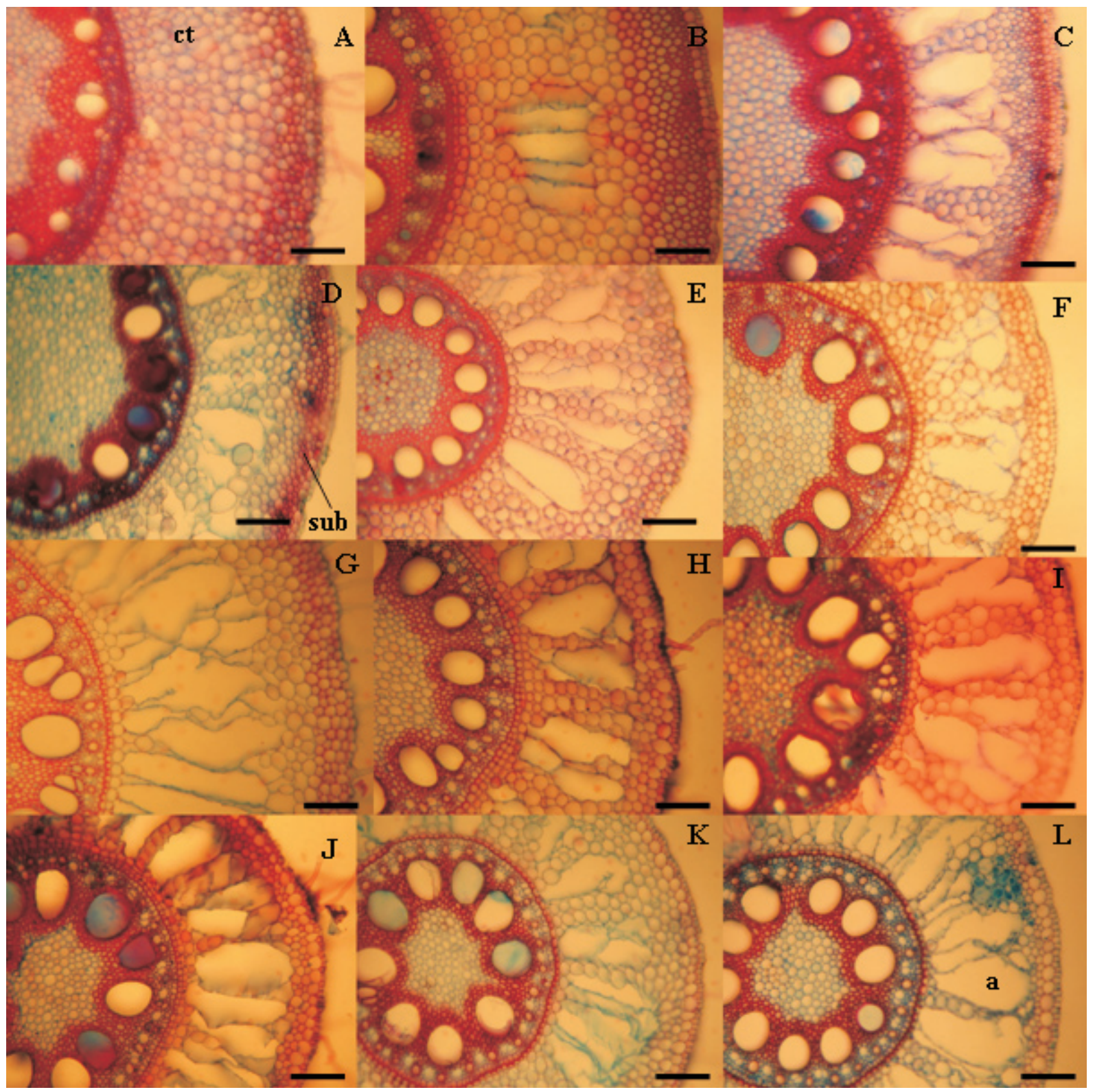

Figura 1. Seções transversais de raízes dos ciclos de seleção do milho 'Saracura' e das testemunhas, sob alagamentos intermitentes, com a progressão na formação de aerênquima e redução nos tecidos corticais e na camada com espessamento na região subepidérmica. $\mathrm{Ct}$, córtex; a, aerênquima sub, camadas subepidérmicas com lignificação. A, BR 107; B, C1; C, C3; D, C5; E, BRS 1010; F, C7; G, C9; H, C11; I, C13; J, C15; K, C17; L, C18. A barra corresponde a $200 \mu \mathrm{m}$. 
já que a formação de aerênquima se dá a partir de $10 \mathrm{~mm}$ da região apical da raiz (Gunawardena, 2008). O comportamento das AAE, em C13 e C15, com o agrupamento em uma classe estatística semelhante à de C5, está relacionado apenas a variações pontuais na resposta das plantas, amostradas nas condições experimentais, pois, como se observa na Tabela 1, em $\mathrm{C} 17$ os valores voltaram a ser englobados na classe imediatamente inferior à do último ciclo, que constituiu o grupo com os maiores valores. Portanto, o aumento da capacidade de formação de aerênquima, adquirido ao longo dos ciclos, foi evidente; contudo foi comparável ao observado por Johnston et al. (2004), em Iris sp., já na primeira geração. Esses resultados, comparados aos da variedade BR 107, estão de acordo com trabalhos anteriores, que relatam a superioridade do milho 'Saracura' em relação a ela, no que se refere a características de tolerância ao alagamento (Vitorino et al., 2001; Alves et al., 2002).

Os valores para a PCV e PC não foram diferentes nos ciclos ou no grupo controle (Tabela 1). Entretanto, houve aumento na PA ao longo dos ciclos, o que indica que a área do córtex se manteve inalterada, mas que grande parte desta área foi disponibilizada para a formação de câmaras de aerênquima, destinadas ao acúmulo de $\mathrm{O}_{2}$. Isto aumentaria a tolerância das plantas a ambientes alagados, por melhorar a difusão desse gás pelos tecidos da raiz, o que é de vital importância para o incremento da tolerância das plantas ao alagamento (Insausti et al., 2001). O aerênquima é necessário para a difusão e convecção dos gases a distâncias maiores que $80 \mathrm{~mm}$ e resulta em melhor oxigenação das células ao longo do tecido (Drew, 1997).

AEC se reduziu ao longo dos ciclos de seleção (Tabela 1 e Figura 1) em 22,6\%, no ciclo $\mathrm{C} 18$, em relação ao $\mathrm{C} 1$, e em $27,5 \%$ em relação à variedade BR107. Redução na espessura do córtex de Cecropia pachystachya, sob condições de alagamento, foi observada por Batista et al. (2008). A formação de aerênquimas pode reduzir de forma significativa a condutividade hidráulica da raiz (Fan et al., 2007), a qual é essencial para a manutenção do fluxo transpiratório e a distribuição de nutrientes pela planta. Portanto, pode-se relacionar a redução na EC com a diminuição da distância necessária para a água chegar ao cilindro vascular, o que melhoraria a condutividade hidráulica.

Essa explicação pode ser também aplicada à diminuição observada na CS da raiz (Tabela 1 e
Figura 1), em que o $\mathrm{C} 18$ apresentou redução de $54,22 \%$, em relação aos ciclos iniciais (C3), e de $48,74 \%$ em relação à variedade BR107. A espessura da camada suberizada, altamente hidrofóbica, pode funcionar como barreira apoplástica à absorção e refluxo de água, como ocorre com a endoderme (Dalla Vechia et al., 1999), e a sua redução deve diminuir a resistência ao fluxo de água para o cilindro vascular, o que contribuiria para a manutenção da condutividade hidráulica da raiz, mesmo com o aumento em PA.

A relação entre a $P C$ - que não se alterou - e a EC reduziu-se ao longo dos ciclos de seleção. Esse resultado pode ser interpretado como um investimento das plantas para manter a área disponível para a formação de aerênquima e ainda manter a condutividade hidráulica, com a redução da espessura do córtex. Podese observar na Figura 2 que a espessura do córtex influi na área total desse tecido.

A geometria do córtex (se aberto como uma faixa) é a de um trapézio, com a base menor formada pelo $\mathrm{CC}$ e a base maior pelo CT, que é delimitado pela epiderme. A altura do trapézio é composta pela distância entre as duas bases perpendiculares e esta é a medida da EC. Pela fórmula utilizada para o cálculo da área do trapézio $\{$ área $=[(\mathrm{b}+\mathrm{B}) \mathrm{h}] / 2\}$, pode-se observar que, para que a área do córtex se mantenha quando ocorre a diminuição da EC, deve-se aumentar os valores de $\mathrm{CC}$ e $\mathrm{CT}$, o que compensaria a diminuição na $\mathrm{EC}$, se a fórmula para a área do córtex for considerada como $\mathrm{AC}=\{[(\mathrm{CC}+\mathrm{CT}) \mathrm{EC}] / 2\}$. A análise dos resultados da Tabela 2 mostra que a proporção entre os perímetros (as bases do trapézio) não se alteram e, portanto, os aumentos ocorrem em ambos os perímetros. É importante frisar que as alterações na anatomia radicular, observadas no presente trabalho, mantêm a área disponível para a formação de aerênquima e, também, a condutividade hidráulica nas plantas, o que contribuiria para a adaptação dessas plantas ao ambiente alagado. Estes fatores estão relacionados com a maior tolerância da variedade Saracura a ambientes alagados, em comparação com outras variedades (Vitorino et al., 2001; Alves et al., 2002), e demonstra a importância do aerênquima como fator de adaptabilidade da planta a esse tipo de ambiente. $\mathrm{O}$ desenvolvimento de aerênquima constitutivo é comum em plantas de ambiente alagado (Voesenek et al., 2006) e seu desenvolvimento, em plantas submetidas ao alagamento, também já foi relatado (Bouranis et al., 2006; Gunawardena, 2008). Dalla Vechia et al. (1999) mencionam ainda que, além 


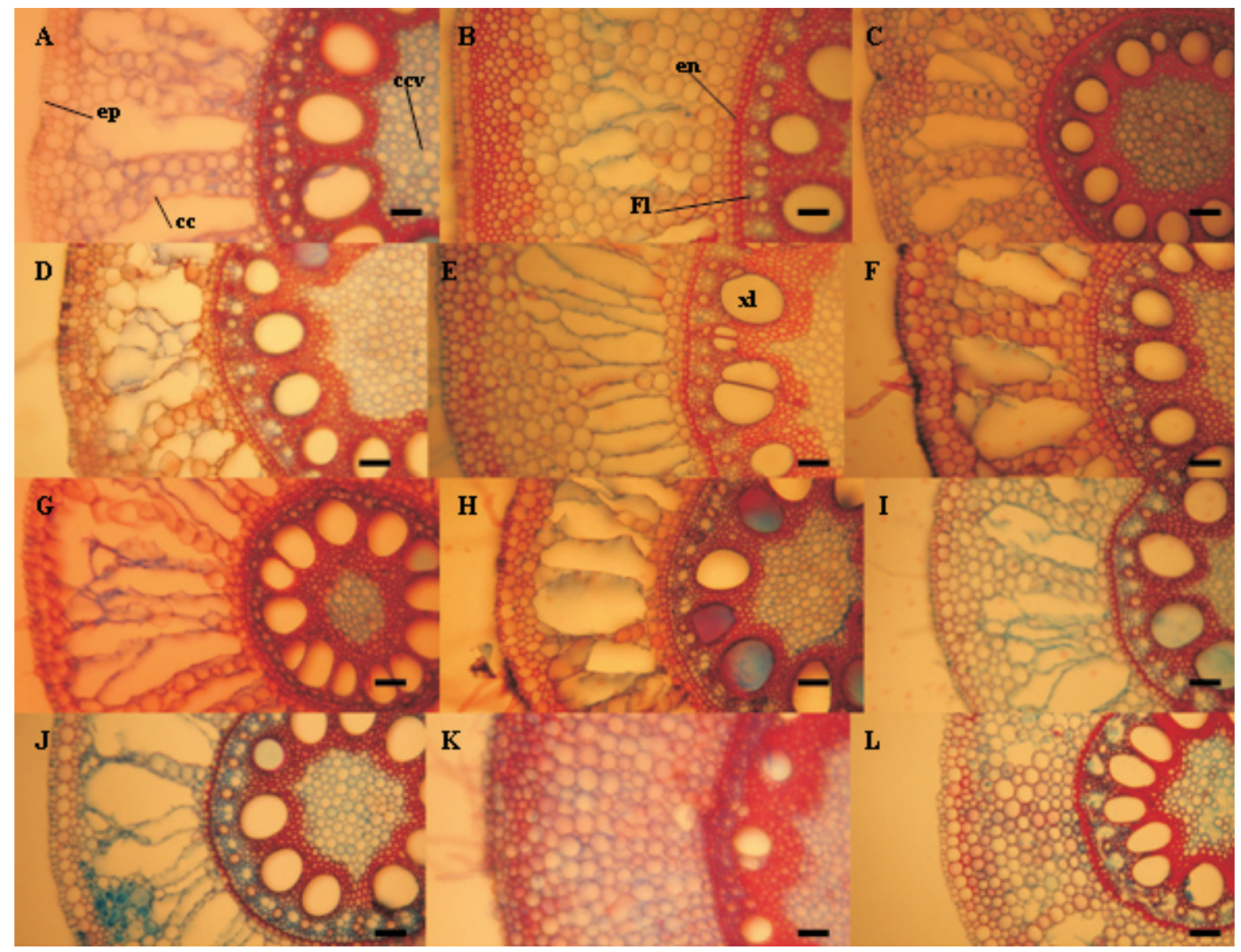

Figura 2. Detalhes de seções transversais das raízes de diferentes ciclos de seleção do milho 'Saracura' e das testemunhas, sob alagamentos intermitentes, em que se identificam as células mensuradas. ep, epiderme; cc, célula do córtex; ccv, célula do cilindro vascular; en, endoderme; Fl, floema. A, C1; B, C3; C, C5; D, C7; E, C9; F, C11; G, C13; H, C15; I, C17; J, C18; K, BR 107; L, BRS 1010. A barra corresponde a $100 \mu \mathrm{m}$.

Tabela 2. Valores observados quanto ao perímetro total da raiz (CT) e do cilindro vascular (CC), e proporção entre esses valores (PP), nos sucessivos ciclos de seleção do milho 'Saracura' e nas cultivares-testemunha, em condições de alagamentos intermitentes ${ }^{(1)}$.

\begin{tabular}{lccc}
\hline $\begin{array}{l}\text { Ciclos de seleção e } \\
\text { testemunhas }\end{array}$ & CT & $\begin{array}{c}\text { CC } \\
\text { C1 }\end{array}$ & PP \\
\hline C3 & $1,10 \mathrm{a}$ & $0,62 \mathrm{a}$ & $0,56 \mathrm{a}$ \\
$\mathrm{C} 5$ & $1,13 \mathrm{a}$ & $0,57 \mathrm{a}$ & $0,45 \mathrm{a}$ \\
$\mathrm{C} 7$ & $0,77 \mathrm{~b}$ & $0,33 \mathrm{~b}$ & $0,43 \mathrm{a}$ \\
$\mathrm{C} 9$ & $1,05 \mathrm{a}$ & $0,57 \mathrm{a}$ & $0,54 \mathrm{a}$ \\
$\mathrm{C} 11$ & $1,13 \mathrm{a}$ & $0,59 \mathrm{a}$ & $0,51 \mathrm{a}$ \\
$\mathrm{C} 13$ & $1,18 \mathrm{a}$ & $0,64 \mathrm{a}$ & $0,55 \mathrm{a}$ \\
$\mathrm{C} 15$ & $0,80 \mathrm{~b}$ & $0,40 \mathrm{~b}$ & $0,49 \mathrm{a}$ \\
$\mathrm{C} 17$ & $0,68 \mathrm{~b}$ & $0,37 \mathrm{~b}$ & $0,54 \mathrm{a}$ \\
C18 & $0,91 \mathrm{~b}$ & $0,47 \mathrm{~b}$ & $0,52 \mathrm{a}$ \\
BR 107 & $1,32 \mathrm{a}$ & $0,65 \mathrm{a}$ & $0,49 \mathrm{a}$ \\
BRS 1010 & $0,99 \mathrm{a}$ & $0,56 \mathrm{a}$ & $0,53 \mathrm{a}$ \\
(1)Médias seguidas por letras iguais, nas colunas, não diferem entre si pelo
\end{tabular}

${ }^{(1)}$ Médias seguidas por letras iguais, nas colunas, não diferem entre si pelo teste de Skott-Knott, a 5\% de probabilidade. da presença dos gases para a respiração radicular, a manutenção da condutividade hidráulica em plantas sob alagamento, é de suma importância.

As células do córtex exibiram aumento em diâmetro, ao longo dos ciclos de seleção, em comparação com as testemunhas (Tabela 3 e Figura 2). Os valores do C18 corresponderam ao aumento de $21,98 \%$, em relação às cultivares BR 107 e BRS 1010. O aumento no tamanho das células corticais está relacionado à diminuição do número de camadas celulares do córtex e à formação de maiores espaços intercelulares, que auxiliam na manutenção de um sistema de difusão de gases contínua com o aerênquima formado, já que células maiores geram espaços intercelulares maiores, por não apresentarem contato em toda a extensão de sua parede celular, o que aumenta a porosidade da raiz (Insausti et al., 2001). 
AEP aumentou em $23,54 \%$, no ciclo C 18 , em relação à variedade $\mathrm{BR} 107$, e 30,49\%, em relação ao híbrido BRS 1010 (Tabela 3 e Figura 2). Esse aumento na epiderme formou dois grupos estatisticamente distintos, e a variedade Saracura foi superior aos controles, na maioria dos ciclos de seleção. O aumento em EP é uma característica favorável da variedade Saracura e pode contribuir para a taxa de sobrevivência e manutenção do sistema radicular, pois forma uma barreira contra a entrada de microrganismos patogênicos (Esaú, 1974) e, também, contra a entrada de substâncias tóxicas presentes em solo alagado (Kozlowski, 1997). Como o ambiente alagado é propício à propagação de bactérias anaeróbias e de substâncias tóxicas (Kozlowski, 1997), a sobrevivência nesse ambiente pode se relacionar com a dificuldade da penetração desses agentes na raiz.

As maiores médias de EN estiveram presentes nos ciclos de seleção do milho 'Saracura' e no híbrido BRS 1010 (Tabela 3 e Figura 2). O ganho em EN também está relacionado à formação de uma barreira apoplástica contra a entrada de patógenos ou ao refluxo de água ou gases (Dalla Vechia et al., 1999), o que contribuiria para a manutenção da condutividade hidráulica radicular.

Foi observada diminuição do DX ao longo dos ciclos de seleção que, com exceção dos ciclos $\mathrm{C} 1$ e C3, foram agrupados com as testemunhas. No ciclo $\mathrm{C} 18$, a diminuição em relação a $\mathrm{C} 1$ foi de $37,4 \%$. Esse comportamento beneficia a planta, pois vasos de xilema, com diâmetro menor, fazem com que a coluna de água encoste mais facilmente nas paredes do elementos de vaso e diminua espaços propícios à formação de bolhas de ar, que causam cavitação (Hacke \& Sperry, 2001). Assim, a diminuição do diâmetro dos vasos é uma característica importante, adquirida durante a seleção do milho 'Saracura'. No entanto, apesar de Vasellati et al. (2001) terem observado a redução no diâmetro do metaxilema de Paspalum dilatatum, em condições de alagamento, esses autores observaram que ela é mais intensa em condições de deficiência hídrica e que ela diminui a condutividade hidráulica das plantas.

A CCV apresentou aumento em diâmetro no último ciclo, bem como na maioria dos outros ciclos, em relação às testemunhas. Contudo, os ciclos $\mathrm{C} 3$ e C17 apresentaram valores semelhantes aos das testemunhas (Tabela 3). A FL foi $60,63 \%$ maior no grupo com as maiores médias desse parâmetro, que inclui as do ciclo C18 e não as dos grupos controle (Tabela 3 e Figura 2). Esse aumento significativo contribui para a adaptação da planta, por auxiliar no fluxo de fotossintatos da parte aérea para as raízes, já que, de acordo com Liao \& Lin (2001), o alagamento reduz o transporte de açúcares pelo floema, o que resulta em acúmulo nas folhas. A produção de ATP é reduzida com a diminuição da quantidade de $\mathrm{O}_{2}$ disponível, já que a rota metabólica é desviada para a anaerobiose (Kozlowski, 1984). A planta necessita de maior quantidade de carboidratos, quando os metaboliza pela glicólise, pois carboidratos são subaproveitados nessa rota. Assim, um aumento na espessura do floema, e a conseqüente facilitação do fluxo de carboidratos nesse tecido, também podem contribuir para que as plantas apresentem maior tolerância ao alagamento.

Tabela 3. Dimensões de células e tecidos radiculares durante os ciclos de seleção do milho 'Saracura' (C1 a C18) e testemunhas (BR 107 e BRS 1010), em condições de alagamentos intermitentes ${ }^{(1)}$.

\begin{tabular}{|c|c|c|c|c|c|c|}
\hline $\begin{array}{l}\text { Ciclos de seleção e } \\
\text { testemunhas }\end{array}$ & $\begin{array}{l}\mathrm{CC} \\
(\mu \mathrm{m})\end{array}$ & $\begin{array}{c}\mathrm{EP} \\
(\mu \mathrm{m})\end{array}$ & $\begin{array}{l}\mathrm{EN} \\
(\mu \mathrm{m})\end{array}$ & $\begin{array}{c}\mathrm{DX} \\
(\mu \mathrm{m})\end{array}$ & $\begin{array}{l}\mathrm{CCV} \\
(\mu \mathrm{m})\end{array}$ & $\begin{array}{c}\mathrm{FL} \\
(\mu \mathrm{m})\end{array}$ \\
\hline$\overline{\mathrm{C} 1}$ & $54,20 \mathrm{~b}$ & $34,07 \mathrm{a}$ & $30,27 \mathrm{a}$ & $149,96 a$ & $46,59 a$ & $71,87 \mathrm{a}$ \\
\hline $\mathrm{C} 3$ & $68,20 \mathrm{a}$ & $34,79 \mathrm{a}$ & $25,45 \mathrm{a}$ & $131,69 b$ & $33,61 b$ & $76,69 \mathrm{a}$ \\
\hline $\mathrm{C} 5$ & $42,42 \mathrm{c}$ & $30,49 b$ & $21,49 b$ & $100,41 \mathrm{c}$ & $37,52 \mathrm{a}$ & $55,35 \mathrm{~b}$ \\
\hline $\mathrm{C} 7$ & $51,56 \mathrm{~b}$ & $27,69 b$ & $21,63 b$ & $111,18 \mathrm{c}$ & $37,57 \mathrm{a}$ & $62,10 \mathrm{~b}$ \\
\hline C9 & $51,34 b$ & $30,12 b$ & $21,95 b$ & $105,88 \mathrm{c}$ & $38,68 \mathrm{a}$ & $54,36 \mathrm{~b}$ \\
\hline $\mathrm{C} 11$ & $50,66 \mathrm{~b}$ & $33,27 \mathrm{a}$ & $28,22 a$ & $102,02 \mathrm{c}$ & $36,08 \mathrm{a}$ & $56,39 a$ \\
\hline C13 & $54,90 \mathrm{~b}$ & $34,02 \mathrm{a}$ & $22,34 b$ & $98,47 \mathrm{c}$ & $36,69 a$ & $72,87 \mathrm{a}$ \\
\hline $\mathrm{C} 15$ & $53,68 b$ & $31,82 \mathrm{a}$ & $21,41 b$ & $96,93 \mathrm{c}$ & $36,99 a$ & $64,19 \mathrm{a}$ \\
\hline $\mathrm{C} 17$ & $52,79 \mathrm{~b}$ & $31,44 a$ & $26,09 \mathrm{a}$ & $100,97 \mathrm{c}$ & $34,47 b$ & $65,84 \mathrm{a}$ \\
\hline $\mathrm{C} 18$ & $54,62 \mathrm{~b}$ & $34,82 \mathrm{a}$ & $24,64 \mathrm{a}$ & $96,04 \mathrm{c}$ & $39,09 a$ & $77,62 \mathrm{a}$ \\
\hline BR 107 & $44,78 \mathrm{c}$ & $28,25 b$ & $22,36 b$ & $93,50 \mathrm{c}$ & $32,84 \mathrm{~b}$ & $48,32 \mathrm{~b}$ \\
\hline BRS 1010 & $44,90 \mathrm{c}$ & $26,68 \mathrm{~b}$ & $25,80 \mathrm{a}$ & $104,70 \mathrm{c}$ & $35,13 \mathrm{~b}$ & $47,58 \mathrm{~b}$ \\
\hline
\end{tabular}

${ }^{(1)}$ Médias seguidas por letras iguais, nas colunas, não diferem entre si pelo teste de Skott-Knott, a $5 \%$ de probabilidade; CC, diâmetro das células corticais; EP, espessura da epiderme; EN, espessura da endoderme; DX, diâmetro das células do xilema; CCV, diâmetro das células do parênquima do cilindro vascular; FL, espessura do floema no cilindro vascular. 


\section{Conclusões}

1. Os sucessivos ciclos de seleção genética da cultivar de milho BRS 4154 Saracura, em solos alagados, promovem avanços expressivos na anatomia radicular para o aumento da tolerância à hipoxia.

2. Os ciclos de seleção da cultivar Saracura resultam em maior desenvolvimento das estruturas de aerênquima e em alterações anatômicas, que melhoram a condutividade hidráulica nas raízes.

\section{Agradecimentos}

À Coordenação de Aperfeiçoamento de Pessoal de Nível Superior, por bolsa concedida; à Embrapa Milho e Sorgo, pelo financiamento do projeto.

\section{Referências}

ALVES, J.D.; MAGALHÃES, M.M.; GOULART, P.F.P.; DANTAS, B.F.; GOUVÊA, J.A.; PURCINO, R.P.; MAGALHÃES, P.C.; FRIES, D.D.; LIVRAMENTO, D.E.; MEYER, L.E.; SEIFFERT, M.; SILVEIRA, T. Mecanismos de tolerância da variedade de milho 'Saracura' (BRS 4154) ao encharcamento. Revista Brasileira de Milho e Sorgo, v.1, p.33-40, 2002.

ANDRADE, A.C.S.; RAMOS, F.N.; SOUZA, A.F.; LOUREIRO, M.B.; BASTOS, R. Flooding effects in seedlings of Cytharexyllum myrianthum Cham. and Genipa americana L.: responses of two neotropical lowland tree species. Revista Brasileira de Botânica, v.22, p.281-285,1999.

BATISTA, C.U.N.; MEDRI, M.E.; BIANCHINI, E.; MEDRI, C.; PIMENTA, J.A. Tolerância à inundação de Cecropia pachystachya Trec. (Cecropiaceae): aspectos ecofisiológicos e morfoanatômicos. Acta Botanica Brasilica, v.22, p.91-98, 2008.

BOURANIS, D.L.; CHORIANOPOULOU, S.N.; KOLLIAS, C.; MANIOU, P.; PROTONOTARIOS, V.E.; SIYIANNIS, V.F.; HAWKESFORD, M.J. Dynamics of aerenchyma distribution in the cortex of sulfate-deprived adventitious roots of maize. Annals of Botany, v.97, p.695-704, 2006.

DALLA VECHIA, F.; CUCCATO, F.; LA ROCCA, N.; LARCHER, W.; RASCIO, N. Endodermis-like sheaths in the submerged freshwater macrophyte Ranunculus trichophyllus Chaix. Annals of Botany, v.83, p.93-97, 1999.

DREW, M.C. Oxigen deficiency and root metabolism: injury and acclimation under hypoxia and anoxia. Annual Review of Plant Physiology and Plant Molecular Biology, v.48, p.223-250, 1997.

ESAÚ, K. Anatomia das plantas com sementes. São Paulo: Edgard Blucher, 1974. 293p.

FAN, M.; BAI, R.; ZHAO, X.; ZHANG, J. Aerenchyma formed under phosphorus deficiency contributes to the reduced root hydraulic conductivity in maize roots. Journal of Integrative Plant Biology, v.49, p.598-604, 2007.

FERRER, J.L.R.; MAGALHÃES,P.C.;ALVES, J.D.;VASCONCELLOS, C.A.;DELUFILHO, N.; FRIES, D.D.; MAGALHÃES, M.M.; PURCINO, A.A.C. Calcium partially relieves the deleterius effect of hypoxia on a maize cultivar selected for waterlogging tolerance. Revista Brasileira de Milho e Sorgo, v.4, p.381-389, 2005.

GUNAWARDENA, A.H.L.A.N. Programmed cell death and tissue remodelling in plants. Journal of Experimental Botany, v.59, p.445-451, 2008.

HACKE, U.G.; SPERRY, J.S. Functional and ecological xylem anatomy. Perspectives in Plant Ecology, Evolution and Sistematics, v.4, p.97-115, 2001.

INSAUSTI, P.; GRIMOLDI, A.A.; CHANETON, E.J.; VASELLATI, V. Flooding induces a suite of adaptive plastic responses in the grass Paspalum dilatatum. New Phytologist, v.152, p.291-299, 2001.

JOHANSEN, D.A. Plant microtechnique. 2.ed. New York: Mc Graw-Hill, 1940, 300p.

JOHNSTON, J.A.; DONOVAN, L.A.; ARNOLD, F.L. Novel phenotypes among early generation hybrids of two Louisiana Iris species: flooding experiments. Journal of Ecology, v.92, p.967-976, 2004.

KOLODYSNKA, A.; PIGLIUCCI, M. Multivariate responses to flooding in Arabidopsis: an experimental evolutionary investigation. Functional Ecology, v.17, p.131-140, 2003.

KOZLOWSKI, T.T. Plant responses to flooding of soil. BioScience, v.34, p.162-167, 1984.

KOZLOWSKI, T.T. Responses of woody plants to flooding and salinity. Tree Physiology Monograph. v.1. 1997.

KRAUS, J.E.; ARDUIM, M. Manual básico de métodos em morfologia vegetal. Seropédica: Edur, 1997. 221p.

LIAO, C.T.; LIN, C.H. Physiological adaptation of crop plants to flooding stress. Proceedings of the National Science Council, v.25, p.148-157, 2001.

MELO, H.C.; CASTRO, E.M.; SOARES, A.M.; MELO, L.A.; ALVES, J.D. Alterações anatômicas e fisiológicas em Setaria anceps Stapf ex Massey e Paspalum paniculatum L. sob condições de deficit hídrico. Hoehnea, v.34, p.145-153, 2007.

VASELLATI, V.; OESTERHELD, M.; MEDAN, D.; LORETI, J. Effects of flooding and drought on the anatomy of Paspalum dilatatum. Annals of Botany, v.88, p.355-360, 2001.

VITORINO, P.G.; ALVES, J.D.; MAGALHÃES, P.C.; MAGALHÃES, M.M.; LIMA, L.C.O.; OLIVEIRA, L.E.M. Flooding tolerance and cell wall alterations in maize mesocotyl during hypoxia. Pesquisa Agropecuária Brasileira, v.36, p.1027-1035, 2001.

VOESENEK, L.A.C.V.; COLMER, T.D.; PIERIK, R.; MILLENAAR, F.F.; PEETERS, A.J.M. How plants cope with complete submergence. New Phytologist, v.170, p.213-226, 2006.

Recebido em 20 de agosto de 2008 e aprovado em 21 de novembro de 2008 